\title{
COחE)-(D̈ES
}

CIENCIA E TECNOLOGIA

\section{PRODUÇÃO E COMÉRCIO LOCAL DE QUEIJO DE COALHO EM MORADA NOVA - CEARÁ}

\author{
Maiara Magna Almeida da Silva, Marlene Nunes Damaceno \\ Instituto Federal de Educação, Ciência e Tecnologia do Ceará - IFCE \\ <maiaramagnaalmeida@gmail.com>,<marlene@ifce.edu.br> \\ $10.21439 /$ conexoes.v15i0.2141
}

\begin{abstract}
Resumo. O queijo de coalho é considerado artefato cultural do Nordeste brasileiro. Popular e versátil, é capaz de satisfazer diferentes grupos econômicos, sociais e étnicos. Este estudo tem por objetivo analisar o perfil de comercialização do queijo de coalho, do tipo artesanal e industrial, de produção local no município de Morada Nova-CE. A metodologia consistiu na pesquisa do tipo observacional e transversal, com controle comparativo de grupos diferentes sem modelo padrão. A coleta de dados foi realizada por meio de um questionário-observação aplicado em supermercados e comércios classificados pelo porte, tipo, origem e marca do queijo comercializada, e a exposição na gôndola. Foram visitados 20 estabelecimentos comerciais distribuídos nos 16 bairros da sede do munícipio, contemplando diferentes perfis de consumidores. Os resultados evidenciaram que a totalidade dos estabelecimentos visitados comercializam o queijo de coalho de produção local, distribuindo-se a oferta nos tipos artesanal e industrial em $85 \%$ e $50 \%$ respectivamente. Os queijos de coalho de produção externa ao município representam apenas $10 \%$ de oferta no comercio local. O queijo de coalho de produção local possui alta aceitação pelos moradanovenses, sendo o de fabricação industrial mais comumente encontrado nos supermercados e de fabricação artesanal nos microcomércios, pois independente do processo de fabricação se industrial ou artesanal o queijo de coalho fabricado no próprio município é capaz de alcançar diferentes grupos sociais.
\end{abstract}

Palavras-chaves: Derivado lácteo. Queijo artesanal. Queijarias.

\section{LOCAL PRODUCTION AND TRADE OF COALHO CHEESE IN MORADA NOVA - CEARA}

\begin{abstract}
Coalho cheese is considered a cultural artifact of Northeastern Brazil. Popular and versatile is able to satisfy different economic, social and ethnic groups. This study aims to evaluate the consumption profile of coalho cheese, of the artisanal and industrial type, of local production in the municipality of Morada Nova-CE. The methodology consisted of observational and cross-sectional research with comparative control of different groups without a standard model. Data collection was carried out by means of an observational questionnaire applied in supermarkets and shops classified by the size, type, origin, and brand of the cheese sold, and the central exposure. Twenty commercial establishments were visited, distributed in the 16 districts seat of the municipality's, covering different consumer profiles. The results showed that all establishments visited commercialized the coalho cheese of local production, with $85 \%$ and $50 \%$ of the offer in artisanal and industrial types, respectively. The coalho cheeses produced outside the municipality represent only $10 \%$ of supply on the local market. Locally produced coalho cheese is highly accepted by locals, being industrially manufactured, most commonly found in supermarkets, and artisanal in commercial stores because regardless of the manufacturing process, if industrial or artisanal, the coalho cheese manufactured in the city itself is capable of reaching different social groups.
\end{abstract}

Keywords: Dairy products. Artisanal cheese. Cheese shops.

\section{INTRODUÇÃO}

A prática do consumo está interligada a vários fatores e estímulos que interferem na escolha por parte do consumidor, tais como suas experiências e tudo o que pensa, são várias etapas, iniciadas pelo desejo e expectativas, seguidas pela busca das opções disponíveis, julgamento, ato da compra, inclusive uma avaliação pes- soal sobre sua experiência com determinado alimento. A influência no poder de decisão do consumidor pode ser motivada por causas internas ou externas, as influências internas são conhecidas e estão relacionadas ao social, psicológico e ainda a situação especifica no momento da aquisição, como o estado emocional. As causas sociais incluem cultura, família e grupos de referência, e as psicológicas estão vinculadas a lições e estilo 
PRODUÇÃO E COMÉRCIO LOCAL DE QUEIJO DE COALHO EM MORADA NOVA - CEARÁ

de vida, motivações, etc (DIóGENES, 2017).

O estudo sobre a prática do consumo ocupa relevante posição entre as mais diversas culturas e isso se dá, pelo entendimento que essa primitiva ação traz possíveis trocas de informação entre produtor e consumidor, com significado positivo e negativo entre ambas as partes, como produzir e consumir e mais recentemente a de construir no ato do consumo, no sentido de externar uma identidade (BARBOSA; CAMPBELL, 2006 e com isso promover o desenvolvimento local, regional entre outras ações.

Existem relatos que a origem da produção de queijo no Brasil, se deu no final do século XVI em Salvador, Bahia, queijos cujo leite, matéria-prima principal, era de ovelha, vaca e cabra. A técnica se expandiu para os demais estados, como Minas Gerais, Pernambuco, Pará, dentre outros, e essa disseminação entre os estados foi responsável pela origem de queijos com características diferentes, sejam estas sensoriais, físico-químicas e microbiológicas (ARAÚJO et al., 2020).

O queijo é considerado o derivado lácteo popularmente mais aceito, seu valor nutricional e sabor característico justificam essa preferência por parte do consumidor. O queijo de coalho é considerado patrimônio cultural do Nordeste brasileiro permanecendo fortemente incorporado a rotina dos nordestinos, constituindo-se em um alimento típico da região. O estado do Ceará é um dos principais produtores, juntamente com os estados de Pernambuco, Rio Grande do Norte e Paraíba. No estado do Ceará, se destaca pela alta produção e consumo ganhando visibilidade (SILVA; SANTOS; SOARES, 2019).

O queijo de coalho possui sabor singular, está presente nas diferentes refeições, petiscos e receitas do nordestino, é destaque entre os queijos artesanais de fabricação e consumo legitimamente regional. As características popular e versátil fazem com que o queijo de coalho seja capaz de satisfazer diferentes grupos econômicos, sociais e étnicos (ALMEIDA; JÚNIOR; GUERRA, 2013).

A valorização dos traços regionais é a principal característica que costuma atrair os consumidores de produtos artesanais. Nesse sentido, mais de 25 mil toneladas de queijo ou requeijão artesanais são vendidas pelos produtores diretamente ao consumidor final e mais de 70 mil toneladas desses produtos são vendidas a intermediários, que fazem a distribuição aos comércios (TAVARES et al., 2019).

O consumo de alimentos artesanais é uma prática tradicional da maioria dos estados brasileiros, e o queijo é um exemplo disso, pois o seu consumo está diretamente associado a cultura local e a tentativa de preser- var características peculiares da região. O processo de produção e as características da matéria prima também constituem importantes fatores que influenciam na qualidade dos queijos artesanais (LIMA et al. 2017).

Segundo o artigo 373 do capítulo V do Regulamento da Inspeção Industrial e Sanitária de Produtos de Origem Animal (RIISPOA):

\begin{abstract}
"Queijo é o produto lácteo fresco ou maturado que se obtém por meio da separação parcial do soro em relação ao leite ou ao leite reconstituído integral, parcial ou totalmente desnatado - ou de soros lácteos, coagulados pela ação do coalho, de enzimas específicas, produzidas por microrganismos específicos, de ácidos orgânicos, isolados ou combinados, todos de qualidade apta para uso alimentar, com ou sem adição de substâncias alimentícias, de especiarias, de condimentos ou de aditivos" (BRASIL 2017. Art. 373).
\end{abstract}

A Lei $\mathrm{n}^{\circ}$ 13.860, de 18 de julho de 2019 define o queijo artesanal

"Considera-se queijo artesanal aquele elaborado por métodos tradicionais, com vinculação e valorização territorial, regional ou cultural, conforme protocolo de elaboração específico estabelecido para cada tipo e variedade, e com emprego de boas práticas agropecuárias e de fabricação. O queijeiro artesanal é responsável pela identidade, pela qualidade e pela segurança sanitária do queijo por ele produzido e deve cumprir os requisitos sanitários estabelecidos pelo poder público. Parágrafo único: $\mathrm{O}$ tempo de cura do queijo feito a partir de leite cru é definido com base no processo tecnológico de produção de cada variedade de queijo, de acordo com suas características." (BRASIL 2019] Art. $1^{\circ}$ e $2^{\circ}$ ).

No mercado de derivados lácteos do Brasil, é possível distinguir os queijos com base nas suas características e processo de produção, definindo-se como queijo de coalho o produto obtido da coagulação do leite pasteurizado com coalho ou com outras enzimas coagulantes adequadas; o queijo de manteiga que é obtido por meio da coagulação do leite pasteurizado e a atividade de ácidos orgânicos, atingindo uma massa dessorada, fundida e com acréscimo de manteiga de garrafa; o queijo minas frescal é o queijo não prensado, salgado, não maturado resultante da coagulação enzimática do leite pasteurizado com coalho ou com outras enzimas coagulantes adequadas, entre outras definições de queijos que são disponíveis no mercado brasileiro de derivados lácteos, como queijo ricota, queijo prato e queijo provolone (BRASIL, 2017).

No município de Morada Nova, Ceará, Brasil, está instalada a maior indústria de derivados lácteos da região Nordeste do Brasil, a Betânia Lácteos, uma importante fonte de emprego e renda que possui seis fabricas na Região, sendo responsável por mais de 2 mil oportunidades de empregos diretos, presente em mais de 55 
PRODUÇÃO E COMÉRCIO LOCAL DE QUEIJO DE COALHO EM MORADA NOVA - CEARÁ

mil pontos de vendas (GIRãO, 2020). É sede ainda, das micro indústrias de derivados lácteos Dona Socorro e Laticínios Karina, esta última atua desde 2009. A produção de queijo no município de Morada Nova, por sua vez não se limita apenas ao ramo industrial, sendo uma atividade bastante executada por pequenos produtores e queijarias. A cidade conta com pelo menos, 10 pequenos produtores de queijo, que possuem essa atividade como a principal fonte de renda para algumas famílias.

Diante do exposto, o objetivo dessa pesquisa é avaliar o perfil de consumo no município de Morada Nova$\mathrm{CE}$, na categoria derivados lácteos, no quesito queijo, relacionando a compra e consumo do queijo de coalho, do tipo artesanal e industrial, de produção local pelos moradonovenses.

\section{METODOLOGIA}

De acordo com González (2020), o pesquisador encontra-se em um lugar privilegiado na pesquisa qualitativa, em pleno exercício e plenitude do abstrato. O acontecimento que ele observa, e expõe as ações realizadas por seres humanos resume as dimensões sociosimbólicas, referidas à maneira como o pesquisador se reconhece e se apresenta diante dos outros. O efeito da absorção das diferentes condições em que os fatos acontecem, contribui e contextualiza todos os processos sensoriais, afetivos e mentais que se interligam a realidade formada pelas condições sociais, econômicas, geográficas, culturais, históricas, tecnológicas e tantas outras.

O estudo observacional é caracterizado pela pesquisa cientifica, quando o pesquisador apenas observa de forma esquematizada e sistemática, sem nenhuma interferência pessoal nos acontecimentos estudados, as observações são registradas e esses dados servem como base para as descrições e análises por parte do pesquisador (GIL, 2019).

Segundo (ZANGIROLAMI-RAIMUNDO; ECHEIMBERG; LEONE 2018), os estudos observacionais apresentam quatro tipos de desenhos, sendo a pesquisa de corte transversal aquela que tem como objetivo, adquirir dados confiáveis e fidedignos à realidade estudada, a fim de possibilitar que o pesquisador elabore conclusões verídicas, promovendo novas chances, que podem instigar novas pesquisas sendo de grande utilidade para estudos descritivos.

A pesquisa transversal, também definida como seccional, ou de prevalência, caracteriza-se por sua realização e análise em um único momento, onde o pesquisador analisa as variáveis seja de indivíduos, situações ou outros dados de seu interesse, permitindo a observação direta por parte do pesquisador, a coleta de informa- ções rápida, sem necessidade de acompanhamento das ações. Esse estudo unicamente descritivo e observacional possui importante relevância, utilizado em muitos países a fim de tornar conhecido características de seus habitantes em determinados momentos e situações e relacionar a fatores a serem analisados (HOCHMAN et al. 2005).

A metodologia utilizada para a execução deste trabalho consistiu na pesquisa de campo, sem intervenção ou manuseio, apenas observacional e transversal, pois foi realizada em um único momento, sem a necessidade de acompanhamento ao longo do tempo (SEVERINO. 2013). Quanto ao tipo de controle adotado foi utilizado o controle comparativo, usando a comparação de grupos diferentes, onde não há presença de um modelo padrão (HOCHMAN et al., 2005).

O local de realização do estudo foi o município de Morada Nova, situado na região do Vale do Jaguaribe, no estado do Ceará, de clima semiárido recebendo a denominação de Terra do Vaqueiro, que está associada a tradição festiva do município. A cidade foi fundada em 2 de agosto de 1876 , possui área de $2.779,23 \mathrm{~km}^{2} \mathrm{e}$ apresenta a pecuária como importante atividade lucrativa que fornece matérias-primas para o abastecimento de agroindústrias, em especial o leite para laticínios de micro, pequeno, médio e grande porte (Prefeitura De Morada Nova, 2020). Atualmente, o município conta com uma população média de 61.548 habitantes que está distribuída em 8 distritos, entre as zonas urbana e rural (Figura 1), com maior concentração da população na sede do município (FERREIRA; BASTOS, 2019).

Figura 1: Localização do município de Morada Nova, Estado do Ceará, Brasil.
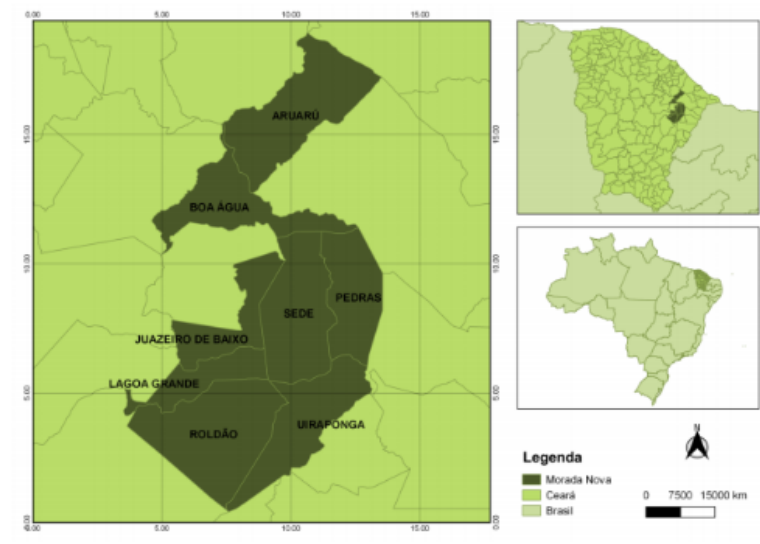

Fonte: Ferreira e Bastos (2019).

A cidade de Morada Nova está constituída atualmente por um conjunto de 16 bairros quais sejam: 2 de 
PRODUÇÃO E COMÉRCIO LOCAL DE QUEIJO DE COALHO EM MORADA NOVA - CEARÁ

Agosto, Alto Tiradentes, Centro, Cristo Rei, Divino Espírito Santo, Girilândia, Hermogênes Henrique Girão, Irapuan Nobre, Julia Santiago, Nossa Senhora da Conceição, Nova Morada, Padre Assis Monteiro, Planalto Aeroporto, São Francisco, São José e Vazantes (FERREIRA; BASTOS, 2019).

Em cada bairro foram identificados e selecionados os estabelecimentos para participação na pesquisa (Tabela 1), seguindo a classificação dos estabelecimentos comerciais que faz referência ao quantitativo de pessoal com vínculo empregatício definida por SEBRAE (2018).

A coleta de dados foi realizada por meio de um questionário-observação (Quadro 1) que foi elaborado para aplicação durante as visitas aos supermercados e comércios localizados na cidade de Morada Nova, Ceará, sede do município. Os elementos de observação foram organizados considerando-se: classificação/categoria e porte do estabelecimento; tipo, origem e marca do queijo comercializada; características de apresentação na gôndola, a fim de, analisar a disponibilidade destes produtos para os consumidores moradanovenses.

A pesquisa foi realizada no primeiro semestre de 2021, e a coleta de informações ocorreu em bairros da zona urbana da sede do município, a cidade de Morada Nova, que atendem diversos públicos e perfis de consumidores em diferentes condições socioeconômicas.

\section{RESULTADOS E DISCUSSÃO}

Foram visitados um total de 20 estabelecimentos, sendo 4 (quatro) supermercados e 16 (dezesseis) comércios, totalizando, pelo menos, 1 (um) estabelecimento por cada bairro da sede, do município de Morada Nova, localizados na zona urbana, que são identificados/reconhecidos como ponto de comercialização de queijo de coalho (Tabela 2).

Dos 20 (vinte) estabelecimentos visitados na pesquisa, 16 (dezesseis) são classificados como: microcomércios, dois (2) como empresas de pequeno porte e outros dois (2) como empresa de médio porte. Nesses estabelecimentos, foi observado que todos realizavam a comercialização do queijo de coalho produzido no município de Morada Nova, Ceará, seja de fabricação industrial ou artesanal (Tabela 2). Isso implica positivamente no comercio local, que independente da escolha pelo processo de fabricação do queijo de coalho, se industrial ou artesanal, os consumidores optam pela oferta dos queijos produzidos na própria cidade.

Segundo Sepúlveda (2017), o consumo local beneficia a dinâmica comercial, onde o fluxo de dinheiro circula internamente, em uma espécie de modelo de eco- nomia fechada, pois a produção e a venda são realizadas na esfera local. As atividades predominantes são agricultura, pecuária e comércios e essa forma de economia surge na tentativa de explorar o máximo do financeiro disponível, evitando que os fluxos monetários circulem fora do ambiente local.

Nas visitas aos supermercados $(n=4)$, foi possível avaliar que todos comercializam o queijo de coalho industrializado e em apenas um desses estabelecimentos foi encontrado o queijo de coalho artesanal (Tabela 2). Com base nesta informação é possível descrever que os supermercados da cidade acolhem melhor a proposta do queijo de coalho industrializado, que representa $100 \%$ de aceitação, sendo encontrado em todos os supermercados visitados, enquanto o queijo artesanal representa apenas $25 \%$, de comercialização, ou seja, ofertado por apenas um desses estabelecimentos.

A menor oferta do queijo artesanal pode ser atribuída as características do produto, pois segundo Almeida, Júnior e Guerra (2013), o queijo de coalho ainda tem sua imagem associada a alimento de segurança alimentar pouco confiável, isso está relacionado a produção artesanal e a probabilidade de contaminação oriundas da matéria-prima, processamento e transporte, sendo necessário a implantação de melhorias na cadeia de produção, a fim de conquistar o status de produto de qualidade, de segurança alimentar assegurada.

Em dois supermercados visitados os queijos industrializados eram predominantemente de marcas locais (Dona Socorro, Karina e Betânia Lácteos). Os outros dois supermercados, além das marcas de indústrias locais, também comercializavam queijos produzidos em outros locais, representando 10

Com relação aos 16 microcomércios visitados na cidade de Morada Nova-CE, estas apresentaram uma oferta diferente em relação aos supermercados, pois a venda de queijo de coalho artesanais, produzidos no próprio munícipio, predominam nestes micros comércios. Dessa forma, enquanto os queijos de coalho artesanais estão presentes em todos os microcomércios visitados, os queijos industrializados foram encontrados em apenas 7 destes estabelecimentos, sendo todos de produção local.

Os resultados encontrados para os microcomércios são opostos aos obtidos para os supermercados, pois enquanto o cliente no supermercado tem preferência pelos queijos industrializados, o consumidor nos microcomércios prioriza o queijo artesanal. Provavelmente, essa diferença esteja relacionada ao perfil do consumidor, que ao escolher os queijos industrializados associe o conhecimento do processo de produção, e o entendimento da indústria ser regida por legislações e regula- 
PRODUÇÃO E COMÉRCIO LOCAL DE QUEIJO DE COALHO EM MORADA NOVA - CEARÁ

Tabela 1: Classificação dos estabelecimentos comerciais segundo o número de trabalhadores empregados (porte).

\begin{tabular}{lll}
\hline \multirow{2}{*}{ Estabelecimento } & \multicolumn{2}{l}{ Número de Pessoas Trabalhando (empregadas) } \\
\cline { 2 - 3 } & Comércio e Serviços & Indústria \\
\hline Microempresa & Até 9 & Até 19 \\
Pequena empresa & De 10 a 49 & De 20 a 99 \\
Média empresa & De 50 a 99 & De 100 a 499 \\
Grande empresa & 100 ou mais & 500 ou mais \\
\hline
\end{tabular}

Fonte: SEBRAE 2018).

Quadro 1: Questionário-observacional de locais de comercialização de queijo de coalho.

\begin{tabular}{|l|l|}
\hline \multicolumn{1}{|c|}{ Estabelecimento } & \multicolumn{1}{c|}{ Descrição } \\
\hline Categoria & ( ) Supermercados ( ) Comercio \\
\hline Porte & ( ) MC ( ) EPP ( ) EMP ( ) GE \\
\hline Queijos de coalho comercializados & ( ) Artesanal ( ) Industrializado \\
\hline Origem dos queijos industrializados & ( ) Morada Nova ( ) Outras cidades \\
\hline & $\begin{array}{l}\text { ( ) Betânia Lácteos } \\
\text { ( ) Karina }\end{array}$ \\
Marcas dos queijos industrializados & ( ) Dona Socorro \\
& ( ) Outras: \\
\hline Origem do queijo artesanal & ( ) Morada Nova ( ) Outras cidades \\
\hline $\begin{array}{l}\text { Alguma marca foi prejudicada pela forma } \\
\text { ou pela quantidade apresentada? }\end{array}$ & $\begin{array}{l}\text { ( ) Não, todas com apresentação e quantidade satisfatória. } \\
\text { ( ) Sim. Quais? }\end{array}$ \\
\hline
\end{tabular}

Legenda: MC: Microcomércio; EPP: Empresa de Pequeno Porte; EMP: Empresa de Médio Porte; GE: Grande Empresa.

Tabela 2: Bairro, da sede do município de Morada Nova, tamanho/porte do estabelecimento, tipo de fabricação, e marca do queijo de coalho, visitado na pesquisa.

\begin{tabular}{|c|c|c|c|c|c|c|}
\hline Bairro & \multicolumn{3}{|c|}{ Estabelecimento comercial } & \multicolumn{3}{|c|}{ Queijo de coalho } \\
\hline Alto Tiradentes & 1 & & & 1 & & \\
\hline Cristo Rei & 1 & & & 1 & 1 & 1 \\
\hline Divino Espírito Santo & 1 & & & 1 & & \\
\hline Irapuan Nobre & 1 & & & 1 & & \\
\hline Julia Santiago & 1 & & & 1 & & \\
\hline Nossa Senhora da Conceição & 1 & & 1 & 1 & 1 & 1 e 2 \\
\hline Nova Morada & 1 & & & 1 & & \\
\hline Pe Assis Monteiro & 1 & & & 1 & 1 & 1 \\
\hline Total & 16 & 2 & 2 & - & - & - \\
\hline
\end{tabular}

Legenda: * Supermercado; ** Marca (queijo industrial): 1 = local; 2 = externa.

mentos técnicos, enquanto os pequenos produtores artesanais são conduzidos pela tradição, despertando no consumidor a dúvida pela segurança alimentar.

Essa relação de conhecimento e confiança que en- 
PRODUÇÃO E COMÉRCIO LOCAL DE QUEIJO DE COALHO EM MORADA NOVA - CEARÁ

volve a elaboração do produto artesanal, poderá se apresentar de forma mais favorável em um futuro próximo, com a aprovação pelo Estado do Ceará, da regulamentação da produção e comercialização de queijos e manteigas artesanais por meio da Lei ${ }^{\circ} 17.318$ de 13 de outubro de 2020, que considera "queijo artesanal o queijo produzido com leite integral, fresco ou refrigerado e cru respeitados os métodos tradicionais, culturais e regionais e com emprego de boas práticas agropecuárias e de fabricação" e dá outras normativas sobre a elaboração.

A fabricação de queijo é uma alternativa para a agricultura familiar, pois segundo Hahn et al. (2017), esta tem participação expressiva na produção de alimentos presentes na alimentação dos brasileiros, sendo uma importante fonte de produção e renda, que responde por aproximadamente $70 \%$ dos alimentos consumidos no Brasil.

Lima e Leal (2017), afirmam que a produção artesanal de queijo se relaciona com os costumes repassados de geração a geração e a tentativa de inserir o pequeno produtor junto ao comercio local, cujo trabalho predominante nestas pequenas queijarias é a mão de obra familiar.

De acordo com a pesquisa, foi possível observar que $100 \%$ dos estabelecimentos visitados comercializam o queijo de coalho de produção local; sendo os de produção industrial são ofertados em $50 \%$ dos estabelecimentos, e os de produção artesanal em $85 \%$ dos estabelecimentos (Figura 2).

Figura 2: Comercialização de queijo de coalho artesanal e industrial por tipo de estabelecimento, na cidade de Morada Nova-CE.

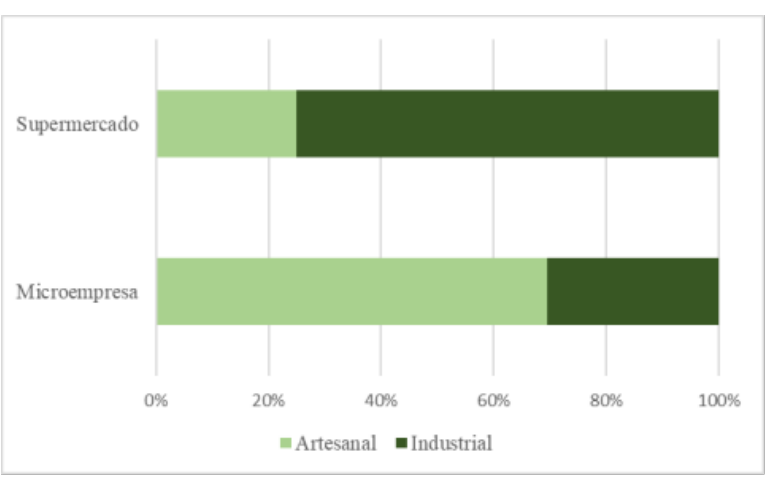

Foi possível observar que o queijo artesanal tem seu maior ponto de vendas nos microcomércios locais, isso pode ter relação com o alcance da distribuição dos pequenos produtores de queijo de coalho, bem como, com a menor exigência dos pequenos comércios em relação a embalagem e acondicionamento destes queijos que geralmente são apresentados em sacos plásticos simples sem identidade e sem rotulagem.
A combinação do conjunto de possibilidades, que valorizam e agregam a percepção das marcas por parte do consumidor é uma estratégia do marketing, ferramenta de importante impacto para empresas empreendedoras que desejam destaque no atual cenário comercial extremamente competitivo, em especial os varejistas, que adotam técnicas para atrair a atenção do consumidor pelo mix de produtos e utilização de recursos estrategistas. Os supermercadistas percebem sua capacidade de chamar a atenção dos clientes para o ponto de venda, com maior frequência, sendo um dos maiores desafios do varejista, independentemente do tamanho do espaço físico de seu comercio a variedade de produtos apresentada (BORGES et al., 2017).

De acordo com Nogueira et al. (2021), o consumo de per capita de queijo no Brasil teve um aumento de $67,8 \%$ entre os anos 2009 e 2019, e atualmente, há uma tendência para o consumo dos queijos artesanais visto sua relação com a origem, o espaço geográfico/regionalidade, a história familiar; entre os queijos artesanais, o queijo de coalho se destaca em função do maior volume estimado de produção.

\section{CONSIDERAÇÕES FINAIS}

O queijo de coalho produzido em Morada Nova-CE, possui forte aceitação pelo comércio local, sendo o de fabricação industrial mais comumente encontrado nos supermercados locais e de fabricação artesanal ofertado em maior quantidade pelos micros comércios da cidade. Independente do processo de fabricação se industrial ou artesanal o queijo de coalho é capaz de alcançar diferentes grupos sociais. Essa considerável inserção dos queijos de coalho, fabricado no próprio município, no comercio local, promove um impacto positivo na economia dos produtores locais, no comercio, bem como aos consumidores da cidade. As evidências do alto consumo do queijo local qualifica a produção dos queijos de Morada Nova.

\section{REFERÊNCIAS}

ALMEIDA, S. d. L.; JÚNIOR, F. G. de P.; GUERRA, J. R. F. Representação da produção e consumo do queijo coalho artesanal. Revista interdisciplinar de gestão social, v. 2, n. 2, p. 37-58, 2013.

ARAÚJO, J. P. A.; CAMARGO, A.; CARVALHO, A.; NERO, L. Uma análise histórico-crítica sobre o desenvolvimento das normas brasileiras relacionadas a queijos artesanais. Arquivo Brasileiro de Medicina Veterinária e Zootecnia, SciELO Brasil, v. 72, n. 5, p. 1845-1860, 2020. 
PRODUÇÃO E COMÉRCIO LOCAL DE QUEIJO DE COALHO EM MORADA NOVA - CEARÁ

BARBOSA, L.; CAMPBELL, C. Cultura, consumo e identidade. Rio de Janeiro: FGV Editora, 2006. 204 p.

BORGES, A. R.; SOARES, S. A.; COELHO, A.; PERSILVA, D. A. A embalagem sedutora na gôndola do supermercado: garantia de atratividade e estímulo ao desejo de consumo do público infantil. Paidéia, ano XII, n. 18, p. 1-11, 2017.

BRASIL. Regulamento da Inspeção Industrial e Sanitária de Produtos de Origem Animal (RIISPOA), 108f. Decreto n. 9.013, de 29 de março de 2017. Regulamenta a Lei n. 1.283, de 18 de dezembro de 1950, e a lei $\mathbf{n}^{\circ} \mathbf{7 . 8 8 9}$, de 23 de novembro de 1989, que dispõem sobre a Inspeção Industrial e Sanitária de Produtos de Origem Animal. Brasília, DF: Diário Oficial da União, 2017. Disponível em: <http://www.queijocoalhobrasil. com/wp-content/uploads/2017/07/decreto-no-9. 013-de-29-de-marco-de-2017_riispoa.pdf>. Acesso em: 20 nov. 2020.

Leis e Decretos. Lei n. 13.860, de 18 de julho de 2019. Dispõe sobre a elaboração e a comercialização de queijos artesanais e dá outras providências. Brasília, DF: Diário Oficial da União, 2019. Disponível em: <http://www.queijocoalhobrasil. com/wp-content/uploads/2017/07/decreto-no-9. 013-de-29-de-marco-de-2017_riispoa.pdf>. Acesso em: 20 nov. 2020.

DIóGENES, M. A força do regionalismo no comportamento de compra:Um estudo do consumo de queijo do tipo coalho. Dissertação (Monografia) Universidade Federal do Ceará, Fortaleza, 2017.

FERREIRA, T. K. S.; BASTOS, J. B. S. Identificação da infraestrutura viária de morada nova por meio de sistemas de informações geográficas. In: $\mathbf{1 6}^{\mathbf{0}}$ CONGRESSO BRASILEIRO DE GEOLOGIA DE ENGENHARIA E AMBIENTAL. São José dos Campos: FATEC-SJC/SP, 2019. cap. Anais..., p. 1-9.

GIL, A. C. Métodos e técnicas de pesquisa social. 7. ed. São Paulo: Atlas, 2019.

GIRãO, L. Betânia lácteos. 2020. Disponível em: <https://www.betanialacteos.com.br/nossa-historia $>$. Acesso em: 07 nov. 2020.

GONZÁLEZ, F. E. Reflexões sobre alguns conceitos da pesquisa qualitativa. Revista Pesquisa Qualitativa, v. 8 , n. 17 , p. 155-183, 2020.

HAHN, C. L.; CASARIN, V. A.; SANTOS, A. V. dos; MIRANDA, R. L. d.; ORTIZ, L. Análise de mercado dos produtos da agroindústria familiar: Estudo de caso do perfil do consumidor e do produtor santo-angelense-rio grande do sul-brasil. Revista Espacios, v. 38, n. 5, p. 1-13, 2017.

HOCHMAN, B.; NAHAS, F. X.; FILHO, R. S. d. O.; FERREIRA, L. M. Desenhos de pesquisa. Acta Cirúrgica Brasileira, SciELO Brasil, v. 20, n. Supl. 2, p. 2-9, 2005.

LIMA, B. B.; LEAL, M. C. Parâmetros indicadores de qualidade de queijos artesanais comercializados em Castro-PR. Dissertação (Trabalho de Conclusão do Curso - Tecnologia em Alimentos) — Universidade Tecnológica Federal do Paraná, Paraná, 2017.

LIMA, M. d. S. F. d.; SILVA, R. A. d.; LIMA, J. L. d.; PORTO, A. L. F.; CAVALCANTI, M. T. H. Queijo de coalho artesanal: fonte alternativa de peptídeos antimicrobianos. Brazilian Journal of Food Technology, SciELO Brasil, v. 20, 2017.

NOGUEIRA, T. S.; SIQUEIRA, K. B.; SOARES, N. D.; CAMPOS, E. W.; MORAES, E. A. P.; VILLELA, R. M. M. B.; DAVID, J. M. N.; GOLIATT, P. V. Z. C.; PIRES, M. F. A.; DINIZ, F. H.; M., N.; VICENTINI, N. M. Tendências de consumo de queijo coalho no Nordeste. 2021. Disponível em: <https: //www.milkpoint.com.br/colunas/kennya-siqueira/ tendencias-de-consumo-de-queijo-coalho-no-nordeste-224698/ $>$ Acesso em: 29 set. 2021.

Prefeitura De Morada Nova. Dados do município. 2020. Disponível em: <https://www.moradanova.ce. gov.br/omunicipio.php> Acesso em: 20 nov. 2020.

SEBRAE. Anuário do trabalho nos pequenos negócios: 2016. 9. ed. São Paulo: DIEESE, 2018.

SEPÚLVEDA, G. E. G. Valoraciones y significaciones acerca del movimiento del dinero en una economía de consumo local. Civitas-Revista de Ciências Sociais, SciELO Brasil, v. 17, n. 1, p. 79-95, 2017.

SEVERINO, A. J. Metodologia do trabalho científico. 1. ed. São Paulo: Cortez, 2013.

SILVA, F. K. B.; SANTOS, L. M. de L.; SOARES, V. F. Aspectos socioeconômicos, produtivos e sanitários da fabricação de queijo coalho em jaguaribe, ceará. Conexões-Ciência e Tecnologia, v. 13, n. 3, p. 41-49, 2019.

TAVARES, A. B.; CAVALCANTI, E. A. N. L. D.; TIMM, C. D.; LIMA, H. G. d.; CERESER, N. D. Queijo artesanal produzido no sul do rio grande 
do sul: avaliação físico-química, microbiológica e suscetibilidade a antimicrobianos de isolados de staphylococcus coagulase positiva. Ciência Animal Brasileira, SciELO Brasil, v. 20, n. 1, p. 1-10, 2019.

ZANGIROLAMI-RAIMUNDO, J.; ECHEIMBERG,

J. d. O.; LEONE, C. Tópicos de metodologia de pesquisa: Estudos de corte transversal. J Hum Growth

Dev, v. 28, n. 3, p. 356-60, 2018. 